\title{
Los Ayuntamientos y el impuesto del Timbre
}

La Ley de Bases de Régimen local de 17 de julio de 1945 proyectó para el futuro la exención de impuestos y contribuciones del Estado que afectaban a las Corporaciones locales, anunciando que en el articulado die la Ley se concretaría el alcance de esta exención (Base $1 .^{a}$ ). Por ser el impuesto del Timbre uno de los que alcanzaban a las Corporaciones locales, hubo de entenderse en la fecha de la publicación de la Ley de Bases que el beneficio fiscal comprendía también el impuesto del Timbre.

Para llegar a apreciar la confusión, que como consecuencia de este precepto tenía que producirse en las esferas administrativas, es preciso conocer cuál era la situación de los Ayuntamientos respecto al mentado impuesto antes del. Decreto Ordenador de las Haciendas locales de 25 de enero de 1946.

La organización y actividad económica de los Ayuntamientos se hallaba regulada en esos pretéritos tiempos por el Libro segundo del Estatuto municipal y el Reglamento de Hacienda municipal de 23 de agosto de 1924. En ninguno de estos textos legales se halla precepto alguno que conceda exención del impuesto del Timbre a los Ayuntamientos. Acudamos a la Ley fiscal sobre el Timbre del Estado de 18 de abril de 1932, y en ella se comprende el capítulo XIV que trata de los documentos en que intervienen los Ayuntamientos, y de él forman parte los artículos 104 y 105 que relacionan los actos y documentos sujetos a timbre. En el propio capítulo, y por medio de los artículos 101 y 102, se sujetan 
a impuesto las licencias que se concedan por los Ayuntamientos para la construcción, mejoras, reparación y ornato de edificios, así como toda clase de licencias que afecten a establecimientos públi$\cos y$. puestos al aire libre en calles y plazas. Completa el artículo 102 la Real Orden de 1 de julio de 1898, que dispone que el impuesto no hay que limitarlo a las licencias de policía y aperturas de establecimientos públicos, sino que hay que extenderlo a cuaiquiera que sea el objeto que motivara la petición o concesión de las licencias.

Del examen del capítulo XIV de la Ley del Timbre se desprende que los únicos documentos referentes a exacciones municipales que se sujetan a impuesto son los referentes a licencias de construcciones y reparaciones de edificios, aperturas de locales de negocio y funcionamiento de establecimientos de pública concurrencia (tales como salas de espectáculos y lugares de diversiones), además de los propios de puestos al aire libre en calles y plazas. Que estas licencias son exacciones, queda bien patente consultando los artículos 368, 374 y 316 del Estatuto. En el primero de estos preceptos citados se relacionan los derechos y tasas por prestación de servicios, y entre ellos se comprenden los conceptos siguientes: licencias para construcciones y licencias de apertura de establecimientos. En el artículo 374 se relacionan los derechos y tasas por aprovechamientos especiales, y entre ellos se comprenden las licencias para industrias callejeras y ambulantes. De la consulta del artículo 316 sacamos la consecuencia de que todos los derechos y tasas son exacciones.

Estableciendo una relación entre el Estatuto municipal y la Ley. del Timbre del Estado de 18 de abril de 1932 llegamos a la conclusión que sólo están sujetos a timbre los derechos o tasas consistentes en licencias de construcciones, apertura y funcionamiento de establecimientos públicos y de negocio, ejercicio de industrias ambulantes e instalación de puestos al aire libre en calles $y$. plazas. Los demás derechos y tasas no se hallan sujetos a impuesto en la Ley del Timbre.

Así las cosas, se publica el Decreto Ordenador de las Haciendas locales de 25 de enero de 1946, y en su artículo 6 se lee: 
"Las exacciones municipales serán : a) Derechos y tasas por aprovechamientos especiales o por prestación de servicios, etc.n, y en su artículo 7 que relaciona derechos y tasas, se comprende las licencias para construcciones y obras y las de apertura de establecimientos. Dada la generalidad de la palabra establecimientos, ha de entenderse que afecta por tanto este derecho o tasa a los establecimientos públicos. En el artículo 11 se entienden comprendidos como derechos y tasas por aprovechamientos especiales los quioscos en la vía pública, los puestos, barracas, casetas de venta en la vía pública o terrenos del común y las licencias para industrias callejeras y ambulantes.

Parangonando estos artículos del Decreto Ordenador con la vigente Ley del Timbre llegamos a la consecuencia que sólo están sujetos al Timbre del Estado los conceptos que acabamos de expresar, quedando por tanto los otros exentos.

Es este Decneto Ordenador la primera disposición articulada de carácter municipal, que recoge los beneficios fiscales que para el futuro concede la Ley de Bases de 17 de julio de 1945. En el artículo 218 se declara esta exención en los siguientes términos: Del impuesto del Timbre por los actos, contratos o documentos en que intervengan, siempre que por ministerio de la Ley les fuese expresamente imputable el pago y no exista facultad legal de repercutirlo sobrc otras personas. En el propio artículo.se dispone que queda facultado el Ministerio de Hacienda para ordenar respecto a la exención del impuesto del Timbre en qué casos ha de ser declarada por el mismo, a solicitud de las Corporaciones, y en cuáles habrá de entenderse otorgada sin necesidad de previo recocimiento.

Consecuencia de esta prescripción es la Orden del Ministerio de Hacienda de 23 de junio de 1947 (1). En ella no encontramos

(1) $1 .^{\circ}$ Se considerarán exentos del Impuesto del Timbre, por modo automático, los Municipios y las Provincias por los actos, contratos y documentos en que intervengan por imperativo inexcusable de su funcion, siempre que no correspondan a ampliaciones de su cometido corporativamente aprobadas, pero carentes de la aprobación del Ministerio de la Gobernación y no incluídas, por modo genérico nacional, entre 
más que confusión. Aparte la incorrecta delimitación de la competencia municipal que nos perfila en su artículo $1 .^{\circ}$, viene a acentuar ese particularismo que inicia el Decreto Ordenador con la frase "a solicitud de las Corporaciones", dejando a la discreción de cada Delegado de Hacienda la deciaración de exención del impuesto, declaraciones que no pueden producirse, puesto que las Corporaciones quedan relevadas por la propia Orden de 23 de junio de 1947 de toda solicitud, al prescribirse que en todos los actos, contratos y documentos en que intervengan por imperativo inexcusable de su función quedan exentas de modo automático y no se nos alcanza en qué actos, contratos y documentos intervienen los Ayuntamientos, sin que pueda repercutirse el impuesto que no lo hagan por imperativo inexcusable de su función. ¿Se habrá querido con esta frase reducir la intervención municipal a la actividad meramente local, separándola de su actuación como colaborador íntimo de la Administración central? Quizás fué ese el espíritu que inspiró la repetida Orden, pero no llegó a plasmar en letra clara e inequívoca.

El particularismo a que hemos aludido, bien pronto dejó sentir sus efectos, $y$ en cada provincia se siguió un criterio. Abella, en su obra "Régimen Local", tras unas jugosas y certeras apostillas a la Orden de 23 de junio de 1947, pone de manifiesto la disparidad de criterios de las Administraciones provinciales, citando los "Boletines Oficiales" de las provincias de Ciudad Real y Tarragona, en los que se insertó la declaración de que los documentos cobratorios no deberán reintegrarse con timbre alguno. En otras provincias se reintegran con 0,25 pesetas por pliego $y$ en otras, con 0,50 pon pliego.

los postulados indeclinables de su gestión. 2. Esta exención no será aplicable cuando concurra la circunstancia de referirse a operaciones con terceros a los que legalmente pueda ser repercutido el impuesto o cuando en la contratación pudiese ser insertada tal cláusula de imputabilidad. 3. Queda delegada en las Delegaciones la declaración correspondiente, cuando sea solicitada por las Corporaciones, tanto por la mayor ilustración que supone el examen directo de documentos y el estudio de sus matices como por la mayor rapidez y eficiencia de la sustanciación, etc. 
Un Ayuntamiento, al amparo de la Orden de 23 de junio de 1947, solicita la exención de determinadas exacciones. La Delegación de Hacienda correspondiente, después de oír los informes preceptuados, sintió dudas sobre la resolución y elevó el expediente a la Dirección General del Timbre. Este Centro directivo dictó acuerdo con fecha 13 de abril de 1948, señalando una norma de gran generalidad en cuanto al ámbito de la exención, subdividida en tres grupos: a) Se relacionan todos los actos, contratos y documentos sujetos al impuesto sin alteración alguna. b) Se relacionan los actos, contratos o documentos cuya exacción se acuerda. c) Se relacionan los actos, contratos o documentos exentos parcialmente al rebajarse su tributación por equiparación al Estado.

Las Inspecciones provinciales del Timbre han hecho de esta resolución, dictada exclusivamente para un Ayuntamiento, como se deduce de su parte dispositiva, norma de general y obligado acatamiento, y giran sus visitas a las Corporaciones locales alegando su amparo. Es curioso observar que el particularismo que encierra una norma de carácter general, como es un Decreso, haya sido derrumbade: por la resolución puesta a una particular solicitud, de la que el Fisco ha hecho precepto absoluto sin que exista declaración expresa a este respecto.

Damos por terminada la parte que podríamos calificar de histórica en el trabajo que desarrollamos, y pasamos a entrar en la estrictamente jurídica del problema planteado respecto al impuesto del Timbre sobre los derechos y tasas, por la resolución de 13 de abril de 1948. El problema es el siguiente: Según la Dirección General del Timbre, los recibos por derechos y tasas están sujetos al impuesto, porque son recibos de cantidad de los comprendidos en el artículo 190 de la Ley del Timbre. ¿Es así en realidad?

Basta leer la rúbrica del capítulo de la Ley del Timbre a que pertenece el artículo 190 para comprender que los recibos por derechos y tasas no están incluídos en este artículo. Dice dicha rúbrica: Documentos expedidos por particulares o sociedades de todas clases. ¿Es un Ayuntamiento una Sociedad? Solamente lo es como propietario de Darecho privado. ¿Los derechos y tasas son cantidades que percibe como tal propietario? ¿Puede algún particular 
percibir exacciores bascind se en títulos de Derecho privado? La contestación, por rotunda, no se hace esperar. No. Entonces, ¿a título de qué percibe el Ayuntamiento los derechos y tasas que, como hemos visto, son exacciones? A título de Corporación, que es, segun el artículo $50^{\circ}$ de la Ley de Régimen local. Y no añadimos de Derecho público porque, como muy bien dice Jordana de Pozas, en nuestro Derecho todas las Corporaciones son de Derecho público.

A mayor abundamiento, los derechos y tasas por ser exacciones, una vez liquidados y no satisfechos, se exige su pago por el procedimiento administrativo de apremio y no mediante el ejercicio de una acción ante los Tribunales ordinarios. Esta facultad que tienen los Ayuntamientos arranca de su carácter de Corporación y de la naturaleza fiscal de los derechos y tasas y sólo como tal Corporación puede imponer y exigir estas exacciones. No se puede equiparar el recibo que da el Ayuntamiento a un vecino arrendatario de un inmueble del que es propietario según las normas de Derecho privado por la satisfacción del precio del arriendo (caso perfectamente encajado en el artículo 190 de la Ley del Timbre) que el que entrega a un carnicero por satisfacción de derecho o tasa al servirse del matadero. $\mathrm{El}$ incluir los derechos y tasas en el artículo 190 en relación con el 186, ambos de la Ley del Timbre, suponen tanto como dar a los derechos y tasas la naturaleza de renta. Esta apreciación cae por su peso solamente con recordar el. carácter fiscal que en las leyes municipales han tenido siempre los derechos y tasas. Pero es que además la Jurisprudencia reiteradamente ha declarado con motivo de fricciones que la Administración ha sostenido con el Fisco que los derechos y tasas no son rentas. La Sentencia de 3 de diciembre de 1935 declara que los derechos o tasas de que pueden ser objeto los cementerios tienen el concepto de arbitrio no de renta. Las Sentencias de 23 y 24 de abril de 1935 disponen que los derechos y tasas, dentro de sus propios límites, no pueden estimarse como verdadera renta 0 fruto civil según declaró la Real Orden de 3 de junio de 1895, y tiene reconocido la Jurisprudencia. Años después vuelve a decir et Tribunal Supremo por medio de las Sentencias de 22 de enero 
y 4 de febrero de 1941: "No debe admitirse la doctrina de que el hecho de percibir arbitrios con ocasión de utilizarse por los vecinos el servicio a que está destinado quepa atribuir a tal percepción el carácter de renta del inmueble.) Se refieren estas sentencias a Mataderos municipales. Muy parecida es la de 17 de junio de 1941, con la diferencia de afectar a los servicios de un mercado municipal.

Pasemos a analizar ahora cuál era el criterio de la Dirección General del Timbre antes de concederse a las Corporaciones locales por la Ley el beneficio de exención de dicho impuesto respecto al gravamen de los recibos justificantes de percepción de derechos y tasas por los Ayuntamientos.

La Circular de la Dirección General del Timbre de 9 de mayo de 1934 dice lo siguiente:

"...que los recibos de cantidad expedidos por los Ayuntamientos y que se hallan sujetos al reintegro establecido en la excepción segunda del artículo 190, en relación con el 186 de la Ley del - Timbre del Estado, son los que se refieren a actos o manifestaciones en que los Ayuntamientos obran como una persona o sociedad cualquiera, exceptuándose los que se refieren a los actos de la Administración, como son las papeletas o recibos para la co. branza de las contribuciones e impuestos, por determinarlo así las Reales Ordenes de 8 de enero de 1879, 20 de febrero de 1883 y 12 de marzo de 1886."

Bien claramente se desprende de su lectura que están exceptuados del timbre los recibos extendidos para la cobranza de derechos y tasas. La razón la da la misma Circular con este doble fundamento: $10^{\circ}$ No interviene el Ayuntamiento al extenderlos como persona o sociedad cualquiera, sino que realiza actos de administración. 2. Las papeletas o recibos para la cobranza de las contribuciones e impuestos están exentos por determinarlo así las Reales Ordenes de 8 de enero de 1879, 20 de febrero de 1883 y 12 de marzo de 1886. Hemos destacado el término impuestos porque la imposición municipal, que son los arbitrios, es una especie dentro del género de las exacciones, amplia denominación que comprende, como dice Marqués Carbó, todos los ingresos de Dere- 
cho público de los Ayuntamientos. Esta comprensión se viene estableciendo en todos los textos legales municipales a partir del Real Decreto de 16 de julio de 1918.

Consecuencia a deducir de la citada Circular es que la Dirección General del Timbre estima en 1934 que los recibos por expedición de derechos y tasas están exentos, con la salvedad de los que revisten la forma de licencias que se expresan en el capítulo XIV de la Ley. Quedan por tanto fuera del alcance del gravamen, entre otros, los documentos justificativos del pago de derechos o tasas por utilización de los servicios de matadero, mercado y cementerio, porque en aquella fecha los servicios que los Ayuntamientos prestan en ellos son estimados como los propios de una entidad y no de una sociedad cualquiera regida por las normas de Derecho privado. Y el Tribunal Supremo refuerza este criterio mediante las sentencias de 23 y 24 de abril y 3 de diciembre de 1935, y 17 de junio de 1941, que declaran que estos bienes son construídos con el destino público de servir una necesidad común de los habitantes del Municipio, como consecuencia de los fines que los Ayuntamientos cumplen y de las obligaciones que tienen impuestas. Por esta razón el Alto Tribunal los exceptúa de contribución territorial.

Esto supuesto, nos es difícil comprender la base técnica del nuevo cambio de orientación al considerar que los derechos o tasas que los Ayuntamientos perciben por servicios de mataderos, mercados y cementerios quedan sujetos al impuesto del Timbre por apresiar que los Ayuntamientos obran a este respecto como personas o scciedades cualesquiera.

\section{A. Rodríguez Más}

